\title{
Lipid Accumulation Product: An Obtainable and Accurate Marker for Predicting Metabolic Syndrome in Kidney Transplant Recipients
}

\section{Chan Liu}

Sun Yat-sen University First Affiliated Hospital

\section{Yitao Zheng}

Sun Yat-sen University First Affiliated Hospital

\section{Xiaoping Wang}

Sun Yat-sen University First Affiliated Hospital

\section{Yanqin Wu}

Sun Yat-sen University First Affiliated Hospital

\section{Chuanbao Chen}

Sun Yat-sen University First Affiliated Hospital

\section{Wenjuan Duan ( $\nabla$ ktx2011@126.com )}

Sun Yat-sen University First Affiliated Hospital https://orcid.org/0000-0001-7410-939X

\section{Xiaopeng Yuan}

Sun Yat-sen University First Affiliated Hospital

\section{Research}

Keywords: Lipid accumulation product, Metabolic syndrome, Kidney transplant recipients, Cardiovascular disease

Posted Date: July 1st, 2021

DOI: https://doi.org/10.21203/rs.3.rs-616369/v1

License: (c) (1) This work is licensed under a Creative Commons Attribution 4.0 International License. Read Full License 


\section{Abstract \\ Background}

Metabolic syndrome (MS) is common in kidney transplant recipients(KTRs) and associated with an increased risk of cardiovascular events. There is a need for accurate, non-invasive methods to predict MS in this population. Lipid accumulation product (LAP) is an effective marker of central lipid accumulation related to high risk of MS, cardiovascular disease(CVD) and diabetes. This study aims to assess the ability of LAP as a marker of MS in KTRs.

\section{Methods}

A total of $92 \mathrm{KTRs}$ were included in this study. The general anthropometries and blood biochemical indexes were measured. Body mass index(BMI), waist-hip ratio (WHR), LAP, HOMA-IR and Framingham risk scores(FRS) were calculated.

\section{Results}

The prevalence of MS was $57.8 \%$ in KTRs. Respectively, $64.1 \%, 16.3 \%$, and $19.6 \%$ of patients with KTRs were at low, intermediate, and high risk of CVD according to FRS categorization. KTRs with MS had significantly higher LAP levels compared to those without MS. LAP was highly correlated with lipid metabolism, abdominal obesity, glucose metabolism and inflammatory factor in KTRs. Our analyses revealed that LAP is an independent risk factor for development of MS. Receiver operating characteristic curve (ROC) analysis showed that LAP was a significant discriminator for prediction of MS in KTRs. The optimal cutoff value for LAP in predicting MS was 39.72 (80.8\% sensitivity, $90 \%$ specificity).

\section{Conclusion}

Our study revealed all adiposity measures of interest present themselves as easy and practical tools for evaluating MS in KTRs and LAP is the best index for the determination of MS in KTRs among them.

\section{Background}

Metabolic syndrome (MS) is a cluster of metabolic disorders, associated with the risk of cardiovascular disease (CVD), such as hypertension, diabetes, dyslipidemia and abdominal obesity [1]. In kidney transplant recipients(KTRs), MS has been shown to be an independent risk factor for new-onset diabetes(NODAT), chronic allograft dysfunction, graft failure and CVD [2]. The prevalence of the MS in KTRs is increased compared with the general population. Previous study indicated that the prevalence of MS was $24.5 \%$ in China, and it is higher (32.4\%) in Chinese elderly [3]. However, another study reported $63 \%$ of the KTRs were defined as MS [4]. 
Based on previous studies, it has been confirmed that CVD was the leading cause of mortality and morbidity in KTRs [5]. Thus, early and accurate diagnosis of MS and prophylaxis can lead to higher survival of KTRs as well as their graft survival. The lipid accumulation product(LAP), which is calculated based on the waist circumference (WC) and serum triglyceride(TG) levels, has been proposed as a useful parameter of visceral lipid over-accumulation [6]. Individuals with higher levels of LAP were at higher risk of CVD, MS, insulin resistance(IR) and diabetes [7, 8]. LAP is an accurate marker of MS in general population $[9,10]$. However, there is little known about the relationship between LAP and MS in KTRs. Thus, we aim to investigate whether LAP is an effective index for MS in KTRs.

\section{Methods}

\section{Study subjects}

A total of 136 KTRs from the outpatient transplant clinics at the East Division of the First Affiliated Hospital, Sun Yat-sen University were evaluated. Clinical information for each recipient was retrieved and assembled from the local electronic database, which was approved by the local Ethics Committee. All recipients provided written informed consent before organ transplant. All recipients had given up smoking and drinking after kidney transplantation(KT).

Exclusion criteria included recipients: 1 . age below 18 years; 2 . with graft loss in the first year; 3 . with more than one time of renal transplant; 4 . with multiple organ transplantation; 5 . with no more than 1 year of follow-up post-transplant ; 6 . with incomplete data. Finally, 92 patients ( 60 males and 32 females) were recruited. This cross-sectional study conducted between March 2020 and December 2020.

\section{Immunosuppression}

All included patients received anti-thymocyte globulin (ATG) for induction therapy. Maintenance regimen included tacrolimus, mycophenolate and corticosteroids. Doses of tacrolimus were titrated to plasma levels of 8 to $10 \mathrm{ng} / \mathrm{mL}$ during the first 3 months and titrated to 5 to $7 \mathrm{ng} / \mathrm{mL}$ by the first year. Follow by a 3-day course of intravenous methyl-prednisolone $500 \mathrm{mg}$ daily, oral intake prednisone was started on $30 \mathrm{mg}$ daily and tapered to a maintenance dose of $5 \mathrm{mg}$ daily within 2 months posttranspant.

\section{Definition}

International Diabetes Federation (IDF) in 2005 was used to define MS. WC $>94 \mathrm{~cm}$ (men) or $>80 \mathrm{~cm}$ (women) along with the presence of two or more of the following: 1. FPG greater than $5.6 \mathrm{mmol} / \mathrm{L}$ (100 $\mathrm{mg} / \mathrm{dl})$ or diagnosed diabetes; 2 . HDL-C $<1.0 \mathrm{mmol} / \mathrm{L}(40 \mathrm{mg} / \mathrm{dl})$ in $\mathrm{men},<1.3 \mathrm{mmol} / \mathrm{L}(50 \mathrm{mg} / \mathrm{dl})$ in women or drug treatment for low HDL-C; $3 . T G>1.7 \mathrm{mmol} / \mathrm{L}(150 \mathrm{mg} / \mathrm{dl})$ or drug treatment for elevated TG; 4. Blood pressure $>130 / 85 \mathrm{mmHg}$ or drug treatment for hypertension [11].

Diabetes mellitus was diagnosed according to the American Diabetes Association(ADA) criteria: 1. hemoglobin $\mathrm{A} 1 \mathrm{c}(\mathrm{HbA} 1 \mathrm{c}) \geq 6.5 \%, 2$. FPG $\geq 7.0 \mathrm{mmol} / \mathrm{L}$, 3. two-hour plasma glucose $\geq 11.1 \mathrm{mmol} / \mathrm{L}$ during 
an oral glucose tolerance test, or 4 . classic symptoms of hyperglycemia or hyperglycemic crisis with a random plasma glucose $\geq 11.1 \mathrm{mmol} / \mathrm{L}$ [12].

\section{Biochemical measurements}

All individuals were wearing only light clothing without shoes and hats when anthropometric measurements were performed. All subjects were measured anthropometric parameters by the same person. Height and weight were measured to minimum recorded unit $0.1 \mathrm{~cm}$ and $0.1 \mathrm{~kg}$ using electronic measurement instrument. WC and hip circumference $(\mathrm{HC})$ were measured to the nearest $0.1 \mathrm{~cm}$. Blood pressure was measured with electronic sphygmomanometers using the standard recommended procedures. Overnight fasting blood samples were collected. Hemoglobin, FPG, TG, total cholesterol (TC), HDL-C, low density lipoprotein-cholesterol (LDL-C), C-reactive protein(CRP), serum creatinine were measured using an automatic biochemistry analyzer (Abbott; Chicago, USA). Fasting insulin (FINS) was measured using an automatic biochemistry analyzer (SIEMENS; New York, USA). Erythrocyte sedimentation rate(ESR) was measured using an automatic biochemistry analyzer (VISION; Shenzhen, China).

\section{Calculation formulas}

The obesity and lipid-related parameters included BMI, WHR and LAP. BMI formula is weight in kilograms divided by height in meters squared. WHR was calculated as waist circumference divided by hip circumference. LAP was calculated as [WC $(\mathrm{cm})-58] \times \mathrm{TG}(\mathrm{mmol} / \mathrm{L})$ in women, and $[\mathrm{WC}(\mathrm{cm})-65] \times T G$ $(\mathrm{mmol} / \mathrm{L})$ in men [7]. The Homeostasis Model Assessment for insulin resistance (HOMA-IR) was computed as follows: FINS (mIU/L) $\times$ FPG (mmol/L)/22.5. A Framingham risk score(FRS) was calculated for each patient as previously described [13].囚10-year and lifetime risk scores for CVD were calculated based on the pooled cohort risk assessment equations as previously described [14]. eGFR was calculated using the creatinine-based Chronic Kidney Disease Epidemiology Collaboration equation (CKD-EPI) [15].

\section{Statistical Analyses}

The data distribution was assessed using the Kolmogorov-Smirnov test. Before statistical analysis, nonnormally distributed parameters were transformed to approximate normal distribution by logarithmic or Sqrt equation. The variables were displayed as mean \pm standard deviation, median (interquartile range), or count (percentage) according to their types. Differences between two groups were determined using Student's $t$-test or Mann-Whitney U test, as appropriate. Pearson correlation tests was used to analyzed anthropometric, biochemical, and pressure parameters with MS components. Univariate analysis to assess the association of individual variable with MS. Variables with a $P$ value $<0.03$ were selected for multivariate logistic regression. Receiver operating characteristic(ROC) curve analyses and $95 \%$ confidence intervals $(\mathrm{Cl})$ were used to assess the ability of parameters to predict MS.

The maximum Youden's index (sensitivity plus specificity - 1) was calculated and used to obtain the optimal cut-off values. All statistical analyses were performed using SPSS version 23.0. $P$-value < 0.05 was considered to be statistically significant. 


\section{Results}

Baseline characteristics were shown in Table 1, The mean age of the recipients was $45.75 \pm 11.22$ years, and $65.22 \%$ of the patients were male. Mean eGFR (estimated glomerular filtration rate) was $66.41 \pm 21.14 \mathrm{ml} / \mathrm{min}^{\star} 1.73 \mathrm{~m}^{2}$. Among $92 \mathrm{KTRs}, 52$ individuals had MS, $57.8 \%$ of KTRs fulfilled the IDF definition for MS in this study. Respectively, $64.1 \%, 16.3 \%$, and $19.6 \%$ of KTRs were at low, intermediate, and high risk of CVD according to FRS score. $39.13 \%, 81.52 \%$ of individuals were diagnosed with diabetes and hypertension in KTRs. Only $9.78 \%$ of patients were diagnosed with diabetes before transplantation. $29.35 \%$ of individuals were diagnosed with NODAT. 
Table 1

Demographic and transplant characteristics of KTRs.

\section{Baseline characteristics}

Baselinecharacteristics

Age, years

Male gender, $n \%$

$\operatorname{eGFR}\left(\mathrm{ml} / \mathrm{min}^{\star} 1.73 \mathrm{~m}^{2}\right)$

10-year risk of CVD(according to FRS)

Low risk of CVD, $\mathrm{n} \%$

Intermediate risk of CVD, $\mathrm{n} \%$

High risk of CVD, n\%

Prior dialysis modality

Hemodialysis, n\%

peritoneal dialysis, $n \%$

none, $n \%$

KT duration, months

Metabolism syndrome, $\mathrm{n}(\%)$

NODAT, n(\%)

Previous DM, n(\%)

Hypertension, $\mathrm{n}(\%)$

HBV positive, $n \%$

HCV positive, $n \%$

Antihypertensive therapy, $\mathrm{n}(\%)$

Lipid lowering therapy, $\mathrm{n} \%$

Uric acid lowering therapy, $\mathrm{n} \%$

eGFR estimated glomerular filtration rate; CVD cardiovascular disease; FRS Framingham risk scores;

NODAT new-onset diabetes; $D M$ diabetes mellitus; $H B V$ hepatitis $\mathrm{B}$ virus; $H C V$ hepatitis $\mathrm{C}$ virus

\section{Total}

$\mathrm{n}=92$

$45.75 \pm 11.22$

60(65.22)

$66.41 \pm 21.14$

59(64.10)

15(16.30)

18(19.60)

70(76.09)

19(20.65)

3(3.26)

$38(17,54)$

52(57.80)

27(29.35)

9(9.78)

75(81.52)

9(9.78)

0

70(76.09)

47(51.09)

63(68.48)

As shown in Table 2, There were no significant differences in age, height, SBP, DBP, uric acid(UA), TC and eGFR between KTRs with and without MS. KTRs with MS had significantly higher LAP levels $[68.96(44.04,78.375)$ vs. $22.54(15.29,32.97)]$ compared to those without MS. KTRs with MS had 
significantly increased weight, BMI, WC, HC, WHR, TG, LDL-C, FBG, HbA1c, FINS, HOMA-IR, CRP, ESR and FRS compared to those without MS, while HDL-C level was significantly lower in KTRs with MS. 
Table 2

Comparison of anthropometric and biochemical profiles between KTRs with MS and without MS

\begin{tabular}{|c|c|c|c|}
\hline Variables & $M S(n=52)$ & Non-MS(n = 40) & $P$ \\
\hline Age (year) & $47.17 \pm 11.09$ & $43.90 \pm 11.25$ & 0.167 \\
\hline Height (m) & $1.64 \pm 0.80$ & $1.62 \pm 0.82$ & 0.171 \\
\hline Weight (kg) & $69.85 \pm 13.25$ & $59.78 \pm 12.04$ & 0.000 \\
\hline BMI (kg/m2) & $25.65 \pm 3.63$ & $22.58 \pm 3.58$ & 0.000 \\
\hline WC (cm) & $92.72 \pm 9.30$ & $81.76 \pm 10.52$ & 0.000 \\
\hline $\mathrm{HC}(\mathrm{cm})$ & $98.26 \pm 6.43$ & $93.77 \pm 7.34$ & 0.002 \\
\hline WHR & $0.94 \pm 0.07$ & $0.87 \pm 0.72$ & 0.000 \\
\hline $\mathrm{SBP}(\mathrm{mmHg})$ & $132.12 \pm 14.17$ & $129.18 \pm 15.55$ & 0.347 \\
\hline $\mathrm{DBP}(\mathrm{mmHg})$ & $82.04 \pm 7.19$ & $82.53 \pm 10.01$ & 0.787 \\
\hline $\mathrm{TG}(\mathrm{mmol} / \mathrm{L})$ & $2.31(1.71,2.63)$ & $1.34(1.04,1.59)$ & 0.000 \\
\hline TC (mmol/L) & $6.17 \pm 1.52$ & $5.83 \pm 1.20$ & 0.248 \\
\hline LDL-C (mmol/L) & $3.83 \pm 1.22$ & $3.29 \pm 1.04$ & 0.026 \\
\hline HDL-C (mmol/L) & $1.19 \pm 0.36$ & $1.51 \pm 0.39$ & 0.000 \\
\hline FPG (mmol/L) & $6.66(5.40,7.18)$ & $5.24(4.80,5.40)$ & 0.000 \\
\hline FINS(mIU/L) & $15.00(7.93,17.87)$ & $8.77(5.90,11.07)$ & 0.000 \\
\hline HOMA-IR & $5.02(1.88,5.73)$ & $2.07(1.26,2.49)$ & 0.000 \\
\hline $\mathrm{Hb}(\mathrm{g} / \mathrm{L})$ & $140.90 \pm 21.56$ & $135.58 \pm 22.69$ & 0.254 \\
\hline eGFR(ml/min*1.73m²) & $65.15 \pm 19.24$ & $68.05 \pm 23.54$ & 0.517 \\
\hline CRP(mg/L) & $2.90(1.00,4.40)$ & $1.48(0.40,1.68)$ & 0.000 \\
\hline $\operatorname{ESR}(\mathrm{mm} / \mathrm{h})$ & $29.67(12.00,43.00)$ & $17.56(8.00,26.75)$ & 0.002 \\
\hline FRS & $11.94 \pm 5.03$ & $8.90 \pm 6.40$ & 0.012 \\
\hline LAP & $68.96(44.04,78.38)$ & $25.54(15.29,32.97)$ & 0.000 \\
\hline \multicolumn{4}{|c|}{$\begin{array}{l}B M I \text { body mass index; } W C \text { waist circumference; } H C \text { hip circumference; } W H R \text { waist-to-hip ratio; } S B P \\
\text { systolic blood pressure; } D B P \text { diastolic blood pressure; } T G \text { triglyceride; } T C \text { total cholesterol; } H D L-C \text { high } \\
\text { density lipoprotein cholesterol; } L D L-C \text { low- density lipoprotein cholesterol; } F P G \text { fasting plasma } \\
\text { glucose; FINS fasting insulin; } H O M A-I R \text { homeostasis model of assessment for insulin resistance } \\
\text { index; } H b \text { hemoglobin; eGFR estimated glomerular filtration rate; } C R P C \text {-reactive protein; } E S R \\
\text { erythrocyte sedimentation rate; } F R S \text { Framingham risk scores; } L A P \text { lipid accumulation product }\end{array}$} \\
\hline
\end{tabular}


LAP was correlated positively and significantly with age, weight, BMI, WC, HC, WHR, SBP, TG, TC, LDL-C, FPG, HbA1C, FINS, HOMA-IR, CRP and FRS ( $\gamma=0.210,0.578,0.634,0.747,0.477,0.669,0.240,0.747$, $0.293,0.405,0.487,0.391,0.624,0647,0.391$ and 0.379 , respectively, $P<0.01$, Table 3 ), while correlating negatively with HDL-C $(\gamma=-0.490, P<0.01$, Table 3$)$. After adjusted age, LAP was not only correlated with the above indexes, but also positively correlated with $\operatorname{ESR}(Y=0.373, P<0.01$, Table 3$)$.

Table 3

The pearson correlation between LAP and anthropometrics, glucolipid metabolism markers.

\begin{tabular}{|c|c|c|c|c|}
\hline Variables & $\mathbf{r}$ & $P$ & $\mathbf{r}$ & $P$ \\
\hline Age (year) & 0.21 & 0.045 & - & - \\
\hline Weight $(\mathrm{kg})$ & 0.578 & 0.000 & 0.455 & 0.000 \\
\hline BMI (kg/m2) & 0.634 & 0.000 & 0.446 & 0.000 \\
\hline WC $(\mathrm{cm})$ & 0.747 & 0.000 & 0.485 & 0.000 \\
\hline $\mathrm{HC}(\mathrm{cm})$ & 0.477 & 0.000 & 0.285 & 0.007 \\
\hline WHR & 0.669 & 0.000 & 0.429 & 0.000 \\
\hline $\mathrm{SBP}(\mathrm{mmHg})$ & 0.240 & 0.021 & 0.246 & 0.020 \\
\hline $\mathrm{DBP}(\mathrm{mmHg})$ & 0.055 & 0.602 & 0.109 & 0.311 \\
\hline $\mathrm{TG}(\mathrm{mmol} / \mathrm{L})$ & 0.747 & 0.000 & 0.919 & 0.000 \\
\hline $\mathrm{TC}(\mathrm{mmol} / \mathrm{L})$ & 0.293 & 0.005 & 0.226 & 0.033 \\
\hline LDL-C (mmol/L) & 0.405 & 0.000 & 0.253 & 0.017 \\
\hline $\mathrm{HDL}-\mathrm{C}(\mathrm{mmol} / \mathrm{L})$ & -0.490 & 0.000 & -0.456 & 0.000 \\
\hline FPG (mmol/L) & 0.487 & 0.000 & 0.329 & 0.002 \\
\hline $\mathrm{FINS}(\mathrm{mIU} / \mathrm{L})$ & 0.624 & 0.000 & 0.281 & 0.008 \\
\hline HOMA-IR & 0.647 & 0.000 & 0.230 & 0.030 \\
\hline CRP(mg/L) & 0.391 & 0.000 & 0.222 & 0.037 \\
\hline $\operatorname{ESR}(\mathrm{mm} / \mathrm{h})$ & 0.175 & 0.097 & 0.373 & 0.000 \\
\hline FRS & 0.379 & 0.000 & 0.379 & 0.000 \\
\hline \multicolumn{5}{|c|}{$\begin{array}{l}B M I \text { body mass index; } W C \text { waist circumference; } H C \text { hip circumference; } W H R \text { waist-to-hip ratio; } S B P \\
\text { systolic blood pressure; } D B P \text { diastolic blood pressure; } T G \text { triglyceride; } T C \text { total cholesterol; } H D L-C \text { high } \\
\text { density lipoprotein cholesterol; } L D L-C \text { low- density lipoprotein cholesterol; } F P G \text { fasting plasma } \\
\text { glucose; FINS fasting insulin; } H O M A \text {-IR homeostasis model of assessment for insulin resistance } \\
\text { index; } H b \text { hemoglobin; } e G F R \text { estimated glomerular filtration rate; } C R P \text { C-reactive protein; } E S R \\
\text { erythrocyte sedimentation rate; } F R S \text { Framingham risk scores; }\end{array}$} \\
\hline
\end{tabular}


The correlation between MS-related parameters (LAP, BMI, WC, WHR, TG, FPG) and MS are shown in Table 4, with age, gender and Post-transplant time adjusted. LAP provided the highest correlation with MS $(r=0.598, p<0.01)$. TG showed the lowest correlation with MS $(r=0.358, p<0.01)$.

Table 4

Correlation between anthropometrics measures (LAP, BMI, WC, WHR, FPG, TG) and MS.

\begin{tabular}{|lll|}
\hline Variables & $\mathbf{r}$ & $\boldsymbol{P}$ \\
\hline Sqrt LAP & 0.598 & 0.000 \\
\hline $\mathrm{BMI}(\mathrm{kg} / \mathrm{m} 2)$ & 0.360 & 0.001 \\
WC(cm) & 0.495 & 0.000 \\
\hline WHR & 0.492 & 0.000 \\
\hline LN TG & 0.358 & 0.001 \\
\hline FPG $($ mmol/L) & 0.371 & 0.000 \\
\hline $\begin{array}{l}B M I \text { body mass index; WC waist circumference; } W H R \text { waist-to-hip ratio; } T G \text { triglyceride; FPG fasting } \\
\text { plasma glucose; LAPlipid accumulation product }\end{array}$ & \\
\hline
\end{tabular}

To dissect potential risk factors of MS in KTRs, we first performed univariate analysis (with odds ratio [OR] unadjusted) for every collected variable (Table 5). The analyses indicated that the following variables were probably related with higher risk of MS (all $P<0.01$ ): BMI, WHR, TG, HDL-C, FPG, FINS, $\mathrm{HbA1c}, \mathrm{HOMA}-\mathrm{IR}, \mathrm{ESR}$ and LAP. Next, we performed multivariable logistic regression analysis adjusted for BMI, WHR, TG, HDL-C, FPG, FINS, HbA1c, HOMA-IR and ESR. The result revealed that LAP (adjusted OR, 1.107 [1.056-1.160]; $P<0.05)$ is an independent risk factor for the development of MS (Table 5). 
Table 5

Logistic Regression Analyses of KTRs Risk Factors of MS

\begin{tabular}{|c|c|c|c|c|}
\hline Variables & Unadjusted OR(95\% Cl) & $P$ & adjusted $\mathrm{OR}(95 \% \mathrm{Cl})$ & $P$ \\
\hline $\mathrm{BMI}(\mathrm{kg} / \mathrm{m} 2)$ & $1.291(1.117-1.493)$ & 0.001 & & \\
\hline WHR & $5.415 E+6(2.800 E+3-1.047 E+10)$ & 0.000 & & \\
\hline $\mathrm{TG}(\mathrm{mmol} / \mathrm{L})$ & $8.436(3.099-22.964)$ & 0.000 & & \\
\hline LDL-C (mmol/L) & $1.578(1.043-2.386)$ & 0.031 & & \\
\hline $\mathrm{HDL}-\mathrm{C}(\mathrm{mmol} / \mathrm{L})$ & $0.085(0.020-.0360)$ & 0.001 & & \\
\hline $\mathrm{FPG}(\mathrm{mmol} / \mathrm{L})$ & $2.878(1.577-5.253)$ & 0.001 & $2.297(1.147,4.599)$ & 0.019 \\
\hline $\mathrm{FINS}(\mathrm{mIU} / \mathrm{L})$ & $1.145(1.050-1.248)$ & 0.002 & & \\
\hline $\mathrm{HbA} 1 \mathrm{c}(\%)$ & $3.080(1.565-6.061)$ & 0.001 & & \\
\hline HOMA-IR & $1.736(1.270-2.373)$ & 0.001 & & \\
\hline $\mathrm{CRP}(\mathrm{mg} / \mathrm{L})$ & $1.344(1.067-1.693)$ & 0.012 & & \\
\hline $\operatorname{ESR}(\mathrm{mm} / \mathrm{h})$ & $1.044(1.014-1.074)$ & 0.004 & $1.061(1.015,1.109)$ & 0.009 \\
\hline FRS & $1.099(1.018-1.186)$ & 0.015 & & \\
\hline LAP & $1.110(1.063-1.160)$ & 0.000 & $1.107(1.056,1.160)$ & 0.000 \\
\hline \multicolumn{5}{|c|}{$\begin{array}{l}B M I \text { body mass index; WC waist circumference; WHR waist-to-hip ratio; } T G \text { triglyceride; } H D L-C \text { high- } \\
\text { density lipoprotein cholesterol; } F P G \text { fasting plasma glucose; FINS fasting insulin; } H O M A-I R \\
\text { homeostasis model of assessment for insulin resistance index; } C R P \text { C-reactive protein; } E S R \\
\text { erythrocyte sedimentation rate; } F R S \text { Framingham risk scores; } L A P \text { lipid accumulation product }\end{array}$} \\
\hline
\end{tabular}

ROC curve analysis showed that LAP had the largest AUC of 0.903 (BMI: 0.744, WC: 0.808, WHR: 0.783, respectively) for prediction of MS in KTRs (Table 6, Fig. 1). The optimal cut-off point of LAP to predict MS in KTRs was 39.72 (80.8 \% sensitivity, 90 \% specificity, Table 6, Fig. 1). ROC curve analysis showed that the optimal cut-off values for other adiposity markers in predicting MS as follows(Table 6): WC: $88.7 \mathrm{~cm}$, BMl: $23.42 \mathrm{~kg} / \mathrm{m} 2$; WHR: $0.90 \mathrm{~cm} / \mathrm{cm}$. 
Table 6

The cut-off, sensitivities, specificities and ROC of each variable for the screening of MS in KTRs

\begin{tabular}{|llllll|}
\hline Variables & Cut-off & Sensitivity & Specificity & AUC $(95 \% \mathrm{Cl})$ & $\boldsymbol{p}$ \\
\hline BMI $(\mathrm{kg} / \mathrm{m} 2)$ & 23.42 & 78.8 & 62.5 & $0.744(0.642,0.864)$ & 0.000 \\
\hline WC $(\mathrm{cm})$ & 88.70 & 71.2 & 82.5 & $0.808(0.717,0.899)$ & 0.000 \\
\hline WHR & 0.90 & 82.7 & 72.5 & $0.783(0.685,0.881)$ & 0.000 \\
\hline LAP & 39.72 & 80.8 & 90 & $0.903(0.842,0.964)$ & 0.000 \\
\hline $\begin{array}{l}\text { BMI body mass index; } W C \text { waist circumference; } \\
\text { product }\end{array}$ & WHR waist-to-hip ratio; LAPlipid accumulation \\
\hline
\end{tabular}

\section{Discussion}

With the improvement of people's living standard, MS is more and more popular nowadays. The MS is a pathologic condition characterized by hypertension, fasting hyperglycemia, IR, dyslipidemia and abdominal obesity [1]. Those diseases all contributed to a reduced life expectancy with an increased mortality for CVD. MS should be more concerned in order to improve quality and expectancy of life and reduce healthcare costs.

Compared to maintenance dialysis(MD), kidney transplantation $(\mathrm{KT})$ is the optimal treatment for end stage kidney disease (ESKD), contributed to significant improvement in survival and quality of life [5]. The burden of CVD in ESKD is reduced after KT. However, the risk of CVD-related morbidity and mortality is still higher in KTRs when compared with the general population [16, 17]. KTRs were at high prevalence of CVD risk factors, such as DM (24-42\%) [18], hypertension (40-90\%) [19, 20] and dyslipidemia (50\%) [21]. Our study revealed that $64.1 \%, 16.3 \%$, and $19.6 \%$ of KTRs were at low, intermediate, and high risk of CVD according to FRS categorization. $39.13 \%$ of individuals were diagnosed with diabetes in KTRs, including $29.35 \%$ subjects were NODAT. The incidence rate of hypertension was as high as $88 \%$. Those results were similar to previous investigation, revealed KTRs were at high risk of CVD. MS has been proved to be an independent risk factor for NODAT in KTRs [2], which can explain the prevalence of NODAT was higher than the general population.

The development or worsening of MS plays a core role in the development of CVD after kidney transplantation. We found that the parameters of lipid metabolism, abdominal obesity, inflammatory factors and glucose metabolism in KTRs with MS were higher than in those without MS, which are contributors to CKD. The prevalence of MS in KTRs is higher than in the general population. A survey in Netherlands in 2004 showed prevalence of MS was about $63 \%$ based on ATP III criteria at a median of 6 years (2.6 to 11.4 years) of 606 KTRs [4]. In another study, prevalence was $32 \%$ in 1 year after kidney transplantation in France [22]. Our study found that $57.8 \%$ of KTRs were defined as MS with a median of 38 months (17 to 54 months) post transplant. It is obviously higher than the general population (24.5\%-32.4\%) in China [3]. The varied prevalence may be related to post-transplant time and ethnics. 
Another study confirmed this, which noted a prevalence of MS was about $22.6 \%$ at 1 year, increased to $37.7 \%$ at the 18 months assessment [23], suggested that the prevalence of MS may increase over time. Besides, immunosuppression may play an important role in the development of the individual components of the MS. Corticosteroids have negative effect on BP, lipid metabolism, inflammatory factor and glucose metabolism. High dosages corticosteroids may stimulate appetite and promote weight gain. Immunosuppressive agents increase the incidence and severity of cardiovascular risk factors. These parameters will improve after the implementation of steroid withdrawal or steroid-free immunosuppression $[24,25,26]$.

So it is rather important to reduce the incidence of MS in KTRs due to the existing high cardiovascular risk. Thus, early and accurate diagnosis of MS and its intervention can lead to decreased risk of CVD and higher survival of KTRs group.

In recent years, more attention has been attracted to visceral obesity. Abdominal obesity is central to the definition of MS. Magnetic resonance imaging (MRI) is the most accurate indicator for the assessment of abdominal obesity [27]. Nevertheless, this method is not suitable for routine clinical use, with a high cost and radiation risk for KTRs. WC, WHR and BMI are commonly used to evaluate abdominal obesity and MS. Body mass index (BMI) is commonly used in the measurement of overall obesity $[28,29]$. There is strong evidence indicating that $\mathrm{BMI}$ is not the ideal obesity measurement, particularly when it is used for the assessment of disease risk [30]. BMI is unable to distinguish between muscle mass and fat mass accurately. WC is the simplest and most economical measure of abdominal obesity [27]. WHR further reflect the fat distribution based on WC, and all three were considered to be specific alternatives to assess abdominal fat [31].

LAP is a developed index of excessive lipid accumulation that can be used for assessing cardiometabolic risk factors [6]. Individuals with higher levels of LAP were at higher risk of CVD, MS, insulin resistance(IR) and diabetes [7, 8]. In our survey, KTRs with MS had significant higher LAP levels compared to those without MS. We also found LAP is an independent risk factor for the development of MS in KTRs, adjusted for BMI, WHR, TG, HDL-C, FINS, HbA1c, HOMA-IR and ESR. Compared with other traditional anthropometric predictor (WC, WHR, BMI), LAP has been proved to be a better predictor for the evaluation of metabolic profiles, IR, diabetes and cardiovascular risks in a general population[6, 32-35]. LAP was also confirmed to be better than WC, BMI and TG to identify MS in polycystic ovary syndrome (PCOS) [36]. However, the ability of LAP to predict MS in KTRs is unknown.

In our study, BMI, WC, WHR and LAP are higher in KTRs with MS. Those have positively correlation with MS, and LAP provided highest correlation with MS, adjusted age, gender and Post-transplant time. Meanwhile, we proved that LAP correlated positively and significantly with the parameters of lipid metabolism, abdominal obesity, glucose metabolism and inflammatory factor in KTRs. It indicated that LAP may be a good predictor for MS in KTRs. In order to prove this, we did ROC analysis in LAP, WHR, BMI, WC. It was showed than LAP is the optimal index for prediction of MS in KTRs. The LAP index had the highest AUC value (0.903). The lager area under the curve, the greater the diagnostic significance of 
MS, indicating that LAP was superior to WHR, BMI and WC in predicting MS in KTRs. In addition, the optimal cut-off value was reported as 39.72 for predicting MS in KTRs. These findings support that the LAP is a superior indicator to predict MS in KTRs.

In previous study, MS has been proved to be an independent risk factor for allograft loss $[4,23]$. Our survey found no significant differences in eGFR between two groups. This may be related to the duration of KT. In our future research, we will follow up KTRs for longer time. In our study, the level of SBP, DBP, UA, TC between KTRs with and without MS had no significant differences. The reason may owe to that most of our patients were taking antihypertensive drugs(76.09\%), lipid-lowering drugs(51.09\%) or uric acid lowering drugs(68.48\%).

As yet, there are some limitations in our study that require emphasis. First, it represents a single-centred cross sectional study characterised by a small sample size. Second, because of limitation of small sample size, we did not separate KTRs by gender. Therefore, further research should be undertaken in larger cohorts and longer duration of KT.

\section{Conclusion}

In summary, this study highlights the role of LAP as an independent risk factor for MS in KTRs. As an easily obtainable measurement, LAP has a reliable and strong diagnostic accuracy for MS in KTRs. Early diagnosis and early intervention could obviously decrease morbidity and mortality rate of CVD. This can not only result in significant improvement in survival and quality of life, but also save healthcare costs.

\section{Abbreviations}

AUC

area under curve; $\mathrm{ATG}$ = anti-thymocyte globulin; $\mathrm{BP}=$ blood pressure; $\mathrm{CVD}=$ cardiovascular disease; $\mathrm{BMI}$ = body mass index; CRP = C-reactive protein; CKD-EPI = chronic kidney disease epidemiology collaboration equation; $\mathrm{Cl}$ = confidence intervals; $\mathrm{DBP}$ = diastolic blood pressure; ESR = erythrocyte sedimentation rate; ESKD = end stage kidney disease; eGFR = estimated glomerular filtration rate; FINS = fasting insulin; FPG = fasting plasma glucose; FRS = Framingham risk scores; $\mathrm{HC}=$ hip circumference; $\mathrm{HDL}-\mathrm{C}=$ high-density lipoprotein cholesterol; HOMA- IR = homeostatic model to assess insulin resistance index; $\mathrm{HbA} 1 \mathrm{c}=$ hemoglobin $\mathrm{A} 1 \mathrm{c} ; \mathrm{Hb}=$ hemoglobin; $\mathrm{HBV}=$ hepatitis $\mathrm{B}$ virus; $\mathrm{HCV}=$ hepatitis $\mathrm{C}$ virus; $\mathrm{ADA}=$ American Diabetes Association; IDF = International Diabetes Federation; IR = insulin resistance; $\mathrm{KT}=$ kidney transplantation; KTRs = kidney transplant recipients; LAP = lipid accumulation product ; LDL-C = highdensity lipoprotein cholesterol; $\mathrm{MD}=$ maintenance dialysis; $\mathrm{MS}=$ metabolism syndrome; $\mathrm{MRI}=$ magnetic resonance imaging; NODAT = new-onset diabetes; OGTT = oral glucose tolerance test; PCOS = polycystic ovary syndrome; SBP = systolic blood pressure; $\mathrm{OR}$ = odd s ratio; $\mathrm{ROC}$ = receiver operating characteristic; $\mathrm{TC}$ = total cholesterol; TG = triglycerides; $\mathrm{UA}=$ uric acid; $\mathrm{WC}=$ waist circumference; $\mathrm{WHR}=$ waist-to-hip ratio. 


\section{Declarations}

\section{Ethics approval and consent to participate}

The study protocol was approved by the Ethics Committee of the First Affiliated Hospital of Sun Yat-Sen University. Written informed consent was obtained from all participants before data collection.

\section{Consent for publication}

Not applicable.

\section{Availability of data and materials}

The datasets used and analyzed during the current study available from the corresponding author on reasonable request.

\section{Competing interests}

The authors declare that they have no conflict of interest.

\section{Funding}

This project was funded by Guangdong regional joint fund Youth Fund Project (No. 2019A1515110673).

\section{Contributions}

C.L and Y.T.Z designed the study, collected data, analyzed data and wrote the paper. C.L and Y.T.Z contributes equally to this work. X.P.W and C.B.C collected data and analyzed data. Y.Q.W edited the paper. W.J.D and X.P.Y conceived the idea, designed the study and edited the paper. All authors have given their permission for submission of this manuscript.

\section{Acknowledgements}

The authors gratefully acknowledge the support of the study participants, study staff, and partner organizations participating in the baseline survey.

\section{Author information}

Chan Liu and Yitao Zheng contributed equally to this work

\section{Affiliations}

Department of General Practice, the First Affiliated Hospital of Sun Yat-Sen University, Guangzhou, China Chan Liu, WenJuan Duan 
Yitao Zheng, Xiaoping Wang, Chuanbao Chen, Xiaopeng Yuan

\section{Department of Interventional Oncology, the First Affiliated Hospital of Sun Yat-Sen University, Guangzhou, China}

Yanqin Wu

\section{Corresponding authors}

Correspondence to Wenjuan Duan or Xiaopeng Yuan.

\section{References}

1. Mohammad G, Saklayen. The Global Epidemic of the Metabolic Syndrome. Curr Hypertens Rep. 2018;20(2):12. https://doi.org/10.1007/s11906-018-0812-z.

2. Porrini E, Delgado $P$, Torres A. Metabolic syndrome, insulin resistance, and chronic allograft dysfunction. Kidney Int Suppl. 2010;119:42-6. https://doi.org/10.1038/ki.2010.422.

3. Li W, Lun Z, Zhang H, Sun Z, Kanu JS, Qiu S, et al. Prevalence of metabolic syndrome in mainland China: a meta-analysis of published studies. BMC Public Health. 2016;16:296. https://doi.org/10.1186/s12889-016-2870-y.

4. Aiko PJ de Vries, Stephan JL, Bakker, Willem J, van Son, Jaap J, Homan van der Heide, RJ, Ploeg, Hauw $T$, The, et al. Metabolic syndrome is associated with impaired long-term renal allograft function; not all components contribute equally. Am J Transplant. 2004;4(10):1675-83. https://doi.org/10.1111/j.1600-6143.2004.00558.x.

5. Janani Rangaswami, Roy O, Mathew R, Parasuraman E, Tantisattamo M, Lubetzky S, Rao, et al. Cardiovascular disease in the kidney transplant recipient: epidemiology, diagnosis and management strategies. Nephrol Dial Transplant. 2019; 34(5):760-773. https://doi.org/0.1093/ndt/gfz053.

6. Kahn HS. The "lipid accumulation product" performs better than the body mass index for recognizing cardiovascular risk: a population-based comparison. BMC Cardiovasc Disord. 2005;5:26. https://doi.org/10.1186/1471-2261-5-26.

7. Kahn HS. The lipid accumulation product is better than BMI for identifying diabetes: a populationbased comparison. Diabetes Care. 2006;29:151-3. https://doi.org/10.2337/diacare.29.1.151.

8. Elisabeth Wehr H-J, Gruber A, Giuliani R, Möller TR, Pieber B, Obermayer-Pietsch. The lipid accumulation product is associated with impaired glucose tolerance in PCOS women. $\mathrm{J}$ Clin Endocrinol Metab. 2011;96:E986-90. https://doi.org/10.1210/jc.2011-0031.

9. Mariano J, Taverna MT, Martínez-Larrad GD, Frechtel. Manuel Serrano-Ríos, Lipid accumulation product: a powerful marker of metabolic syndrome in healthy population. Eur $\mathrm{J}$ Endocrinol. 2011;164:559-67. https://doi.org/10.1530/EJE-10-1039.

10. Mariana L, Tellechea F, Aranguren MT, Martínez-Larrad M, Serrano-Ríos MJ, Taverna, Gustavo D, Frechtel. Ability of lipid accumulation product to identify metabolic syndrome in healthy men from 
Buenos Aires. Diabetes Care. 2009;32:e85. https://doi.org/10.2337/dc08-2284.

11. K George MM, Alberti P, Zimmet J, Shaw, IDF Epidemiology Task Force Consensus Group. The metabolic syndrome-a new worldwide definition. Lancet. 2005;30(9491):1059-62. https://doi.org/10.1016/S0140-6736(05)67402-8. 366 ) .

12. American Diabetes Association, (2) Classification and diagnosis of diabetes. Diabetes Care. $2015 ; 38$ Suppl:S8-S16. https://doi.org/10.2337/dc15-S005.

13. Peter WF, Wilson SR, Bozeman, Tanya M, Burton DC, Hoaglin R, Ben-Joseph CL, Pashos, et al. Prediction of first events of coronary heart disease and stroke with consideration of adiposity. Circulation. 2008;118:124-30. https://doi.org/10.1161/CIRCULATIONAHA.108.772962.

14. David C, Goff Jr DM, Lloyd-Jones G, Bennett S, Coady, Ralph B, D'Agostino R, Gibbons, et al. 2013 $\mathrm{ACC} / \mathrm{AHA}$ guideline on the assessment of cardiovascular risk: a report of the American college of cardiology/American heart association task force on practice guidelines. J Am Coll Cardiol. 2014;129(25 Suppl 2):49-73. https://doi.org/10.1161/01.cir.0000437741.48606.98.

15. Andrew S, Levey LA, Stevens CH, Schmid YL, Zhang, Alejandro F, Castro 3rd, Harold I, Feldman, et al. CKD-EPI, A new equation to estimate glomerular filtration rate. Ann Intern Med. 2009;150(9):604-12. https://doi.org/10.7326/0003-4819-150-9-200905050-00006.

16. Nagesh S, Anavekar JJV, McMurray EJ, Velazquez SD, Solomon L, Kober J-L, Rouleau, et al. Relation between renal dysfunction and cardiovascular outcomes after myocardial infarction. N Engl J Med. 2004;351:1285-95. https://doi.org/10.1056/NEJMoa041365.

17. Arend SM, Mallat MJ, Westendorp RJ, van der Woude FJ, van Es LA. Patient survival after renal transplantation; more than 25 years follow-up. Nephrol Dial Transplant. 1997;12:1672-9. https://doi.org/10.1093/ndt/12.8.1672.

18. Bertram L, Kasiske JJ, Snyder D, Gilbertson, Arthur J, Matas. Diabetes mellitus after kidney transplantation in the United States. Am J Transplant. 2003;3:178-85. https://doi.org/10.1034/j.1600-6143.2003.00010.x.

19. Bertram L, Kasiske S, Anjum R, Shah J, Skogen C, Kandaswamy B, Danielson, et al. Hypertension after kidney transplantation. Am J Kidney Dis. 2004;43:1071-81. https://doi.org/10.1053/j.ajkd.2004.03.013.

20. Premasathian NC, Muehrer R, Brazy PC, Pirsch JD, Becker BN. Blood pressure control in kidney transplantation: therapeutic implications. J Hum Hypertens. 2004; 18: 871-7. https://doi.org/ 10.1038/sj.jhh.1001767.

21. Badiou S, Cristol JP, Mourad G. Dyslipidemia following kidney transplantation: diagnosis and treatment. Curr Diab Rep. 2009;9(4):305-11. https://doi.org/10.1007/s11892-009-0047-0.

22. Cécile Courivaud A, Kazory D, Simula-Faivre J-M, Chalopin D, Ducloux. Metabolic syndrome and atherosclerotic events in renal transplant recipients. Transplantation. 2007;83:1577-81. https://doi.org/10.1097/01.tp.0000266898.93894.3d.

23. Esteban Porrini P, Delgado C, Bigo A, Alvarez M, Cobo, María D, Checa, et al. Impact of metabolic syndrome on graft function and survival after cadaveric renal transplantation. Am J Kidney Dis. 
2006; 48:134 - 42. https://doi.org/10.1053/j.ajkd.2006.04.078.

24. Roberto, Marcén. Immunosuppressive drugs in kidney transplantation: impact on patient survival, and incidence of cardiovascular disease, malignancy and infection. Drugs. 2009;69(16):2227-43. https://doi.org/10.2165/11319260-000000000-00000.

25. Knight SR, Morris PJ. Steroid avoidance or withdrawal after renal transplantation increases the risk of acute rejection but decreases cardiovascular risk: A meta-analysis. Transplantation. 2010;89:114. https://doi.org/10.1097/TP.0b013e3181c518cc.

26. Donald E. Hricik. Metabolic Syndrome in Kidney Transplantation: Management of Risk Factors. Clin J Am Soc Nephrol. 2011;6:1781-5. https://doi.org/10.2215/CJN.01200211.

27. Hongjuan Fang E, Berg X, Cheng W, Shen. How to best assess abdominal obesity. Curr Opin Clin Nutr Metab Care. 2018;21(5):360-5. https://doi.org/10.1097/MC0.0000000000000485.

28. Aydin M, Bulur S, Alemdar R, Yalçin S, Türker Y, Basar C, et al. The impact of metabolic syndrome on carotid intima media thickness. Eur Rev Med Pharmacol Sci. 2013;17:2295-301.

29. Furuncuoğlu Y, Tulgar S, Dogan AN, Cakar S, Tulgar YK, Cakiroglu B. How obesity affects the neutrophil/lymphocyte and platelet/lymphocyte ratio, systemic immune-inflammatory index and platelet indices: a retrospective study. Eur Rev Med Pharmacol Sci. 2016;20:1300-6.

30. Evans PD, McIntyre NJ, Fluck RJ, McIntyre CW, Maarten W, Taal. Anthropomorphic measurements that include central fat distribution are more closely related with key risk factors than BMI in CKD stage 3. PLoS One. 2012;7(4):e34699. https://doi.org/10.1371/journal.pone.0034699.

31. Danijela Budimir A, Jeroncic G, Gunjaca I, Rudan O, Polasek M, Boban. Sex-specific association of anthropometric measures of body composition with arterial stiffness in a healthy population. Med Sci Monit. 2012;18:CR65-71. https://doi.org/10.12659/msm.882457.

32. Tian Tian H, Pei Z, Chen G, Hailili S, Wang Y. Sun, et al. Comparison of lipid accumulation product and body mass index as indicators of diabetes diagnosis among 215,651 Chinese adults. Peer J. 2020;8:e8483. https://doi.org/10.7717/peerj.8483.

33. Nayeon Ahn SE, Baumeister U, Amann W, Rathmann A, Peters C, Huth, et al. Visceral adiposity index (VAl), lipid accumulation product (LAP), and product of triglycerides and glucose (TyG) to discriminate prediabetes and diabetes. Sci Rep. 2019;9(1):9693. https://doi.org/10.1038/s41598019-46187-8.

34. Mariano J, Taverna MT, Martínez-Larrad GD, Frechtel. Manuel Serrano-Ríos, Lipid accumulation product: a powerful marker of metabolic syndrome in healthy population. Eur $\mathrm{J}$ Endocrinol. 2011;164(4):559-67. https://doi.org/10.1530/EJE-10-1039.

35. Xia C, Li R, Zhang S, Gong L, Ren W, Wang Z, et al. Lipid accumulation product is a powerful index for recognizing insulin resistance in non-diabetic individuals. Eur J Clin Nutr. 2012;66(9):1035-8. https://doi.org/10.1038/ejcn.2012.83.

36. Xiang S, Hua F, Chen L, Tang Y, Jiang X, Liu Z. Lipid accumulation product is related to metabolic syndrome in women with polycystic ovary syndrome. Exp Clin Endocrinol Diabetes. 2013;121(2):115-8. https://doi.org/10.1055/s-0032-1333261. 
Figures

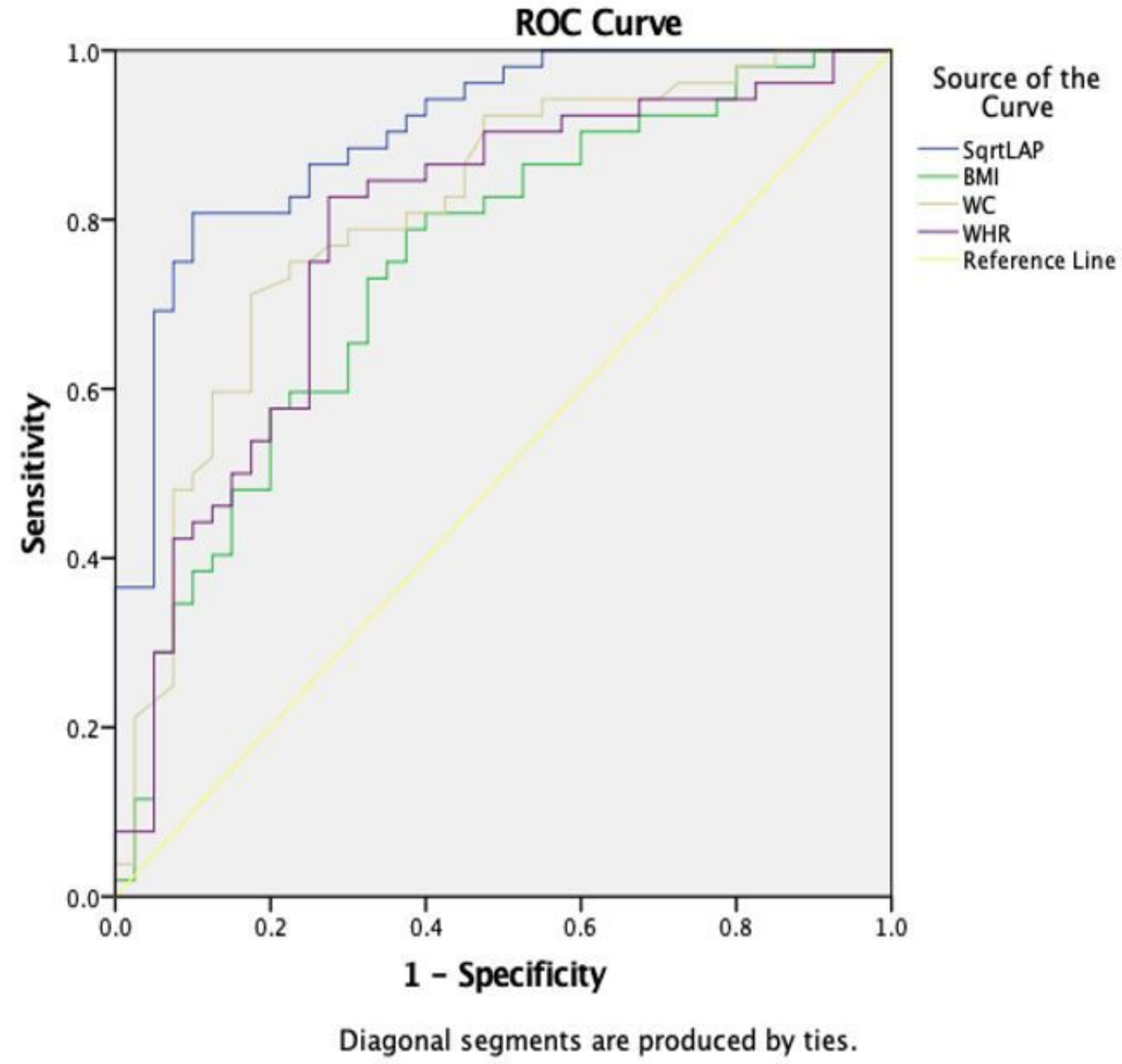

Figure 1

The ROC analysis of adiposity markers in predicting MS in KTRs BMI body mass index; WC waist circumference; WHR waist-to-hip ratio; LAP lipid accumulation product 